\title{
Pacific
}

Journal of

Mathematics

\section{COBCAT AND SINGULAR BORDISM}

\author{
A. K. DAS AND S. S. KhaRE
}

Volume $155 \quad$ No. 2 


\title{
COBCAT AND SINGULAR BORDISM
}

\author{
A. K. Das AND S. S. KhaRe
}

Dold proved that a homomorphism $\phi: H^{n}(\mathrm{BO}) \rightarrow \mathbb{Z}_{2}$ corresponds to a manifold $M^{n}$ if and only if $\phi\left(\mathrm{Sq}^{p} u+v_{p} \cdot u\right)=0, \forall p \geq 0$ and $\forall u \in H^{n-p}(\mathrm{BO}), v_{p}$ being the Wu class. The object of the present work is to have a singular analogue of this result and to study the bordism classification of singular manifolds in $\mathrm{BO}$.

1. Introduction. Singh [1] has developed the notion of cobcat for a manifold $M^{n}$ and has classified, upto bordism, all manifolds $M^{n}$ with $\operatorname{cobcat}\left(M^{n}\right) \leq 3$. $\operatorname{Cobcat}\left(M^{n}\right)$ was defined to be the smallest positive integer $k$ such that the number $\left\langle W_{i_{1}} \cdots W_{i_{p}},\left[M^{n}\right]\right\rangle=0$ for all partitions $i_{1}+\cdots+i_{p}=n$ with $k \leq p \leq n$.

Here we develop the notion of cobcat for a singular manifold $\left(M^{n}, f\right)$ in a space $X$ and discuss the bordism classification of all singular manifolds $\left(M^{n}, f\right)$ in BO with $\operatorname{cobcat}\left(M^{n}, f\right) \leq 3, n=2^{r}$.

Here all the manifolds are to be unoriented, smooth and closed, and all the homology and cohomology coefficients are to be in $\mathbb{Z}_{2}$. The space $X$ is such that for each $n, H_{n}(X)$ and hence $H^{n}(X)$ is a finite dimensional vector space over $\mathbb{Z}_{2}$.

We are thankful to Dr. H. K. Mukharjee of NEHU (India) for giving helpful suggestions. The first author is also grateful to NBHM for its financial support during the course of this work.

2. Preliminaries. Consider the set $N_{n}(X)$ of bordism classes of $n$ dimensional singular manifolds $\left(M^{n}, f\right)$ in $X, f: M^{n} \rightarrow X$ being a continuous map. We know that $N_{n}(X)$ is an abelian group under the operation "disjoint union"

$$
\left[M_{1}^{n}, f_{1}\right]+\left[M_{2}^{n}, f_{2}\right]=\left[M_{1}^{n} \sqcup M_{2}^{n}, f_{1} \sqcup f_{2}\right],
$$

where $f_{1} \sqcup f_{2}: M_{1}^{n} \sqcup M_{2}^{n} \rightarrow X$ is given by

$$
f_{1} \sqcup f_{2}(x)= \begin{cases}f_{1}(x) & \text { if } x \in M_{1}^{n}, \\ f_{2}(x) & \text { if } x \in M_{2}^{n} .\end{cases}
$$

Further, we have

$$
N_{*}(X)=\bigoplus_{n \geq 0} N_{n}(X)
$$


We know that for a point, $N_{*}(p t)=N_{*}$, the unoriented bordism ring, and there is a $N_{*}$-module structure in $N_{*}(X)$ given by

$$
\left[M^{n}, f\right] \times\left[N^{m}\right]=\left[M^{n} \times N^{m}, f \pi\right],
$$

where $\pi: M^{n} \times N^{m} \rightarrow M^{n}$ is the projection.

For a singular manifold $\left(M^{n}, f\right)$ in $X$ let $\tau: M^{n} \rightarrow \mathrm{BO}$ be the classifying map of the tangent bundle over $M^{n}$. Then there is defined a homomorphism $t: H^{n}(\mathrm{BO} \times X) \rightarrow \mathbb{Z}_{2}$ given by

$$
t(w \otimes x)=\left\langle(\tau, f)^{*}(w \otimes x),\left[M^{n}\right]\right\rangle=\left\langle\tau^{*}(w) f^{*}(x),\left[M^{n}\right]\right\rangle,
$$

where $w \otimes x \in H^{n}(\mathrm{BO} \times X)=\bigoplus_{i=0}^{n} H^{n-i}(\mathrm{BO}) \otimes H^{i}(X)$ and $(\tau, f)$ : $M^{n} \rightarrow \mathrm{BO} \times X$ is given by $(\tau, f)(z)=(\tau(z), f(z))$.

The number $\left\langle W_{i_{1}} \cdots W_{i_{r}} f^{*}\left(x_{n-p}\right),\left[M^{n}\right]\right\rangle$ is called the StiefelWhitney number of $\left(M^{n}, f\right)$ associated to the cohomology class $x_{n-p} \in H^{n-p}(X)$ corresponding to the partition $i_{1}+\cdots+i_{r}=p$. Moreover, this number is as usual bordism invariant [2].

Analogous to [1], given a singular manifold $\left(M^{n}, f\right)$ in $X$ there is associated a Poincaré algebra $P^{*}$ given as follows:

Let $J=\left\{z \in H^{*}(\mathrm{BO} \times X)\right.$ : either $\operatorname{dim} z>n$, or for all $z^{\prime} \in$ $\left.H^{n-\operatorname{dim} z}(\mathrm{BO} \times X),\left\langle(\tau, f)^{*} z(\tau, f)^{*} z^{\prime},\left[M^{n}\right]\right\rangle=0\right\}$.

It is easy to see that $J$ is an ideal of the graded algebra $H^{*}(\mathrm{BO} \times X)$. Set

$$
P^{*}=\frac{H^{*}(\mathrm{BO} \times X)}{J}, \text { the quotient algebra. }
$$

Let $q: H^{*}(\mathrm{BO} \times X) \rightarrow P^{*}$ be the quotient map. Clearly, $P^{*}=0$ if and only if $\left(M^{n}, f\right)$ bounds. Let $z \in H^{*}(\mathrm{BO} \times X)$; we say, " $z=0$ in $P^{*}$ " if $q(z)=0$.

As in [1], we have the following proposition, whose verification is a routine matter.

Proposition 2.1. If $\left(M^{n}, f\right)$ is not a boundary then

(a) $P^{*}$ is an $n$-dimensional graded algebra with Poincaré duality,

(b) the Steenrod algebra acts on $P^{*}$ with the action given by

$$
\mathrm{Sq}^{i}(q(z))=q\left(\mathrm{Sq}^{i}(z)\right),
$$

(c) if $z \in H^{n}(\mathrm{BO} \times X)$ then $q(z)=0$ if and only if

$$
t(z)=\left\langle(\tau, f)^{*} z,\left[M^{n}\right]\right\rangle=0 .
$$

It is easy to see that for all $p \geq 0$, and for all $z \in H^{n-p}(\mathrm{BO} \times X)$,

$$
t\left(\mathrm{Sq}^{p}(z)+\left(v_{p} \otimes 1\right) z\right)=0,
$$

where $v_{p} \in H^{p}(\mathrm{BO})$ is the $\mathrm{Wu}$ class. So, in view of the above proposition, we have $\operatorname{Sq}^{p}(z)=\left(v_{p} \otimes 1\right) z$ in $P^{*}$. 
3. Extension of Dold's and Milnor's results to singular case. Dold [3] has proved the following

Result 3.1. For each integer $n \geq 0$, if $\phi: H^{n}(\mathrm{BO}) \rightarrow \mathbb{Z}_{2}$ is a homomorphism then there is an $n$-dimensional closed manifold $M^{n}$ with $\phi(w)=\left\langle\tau(w),\left[M^{n}\right]\right\rangle$ for all $w \in H^{n}(\mathbf{B O})$ if and only if $\phi\left(\mathrm{Sq}^{p}(u)+\right.$ $\left.v_{p} \cdot u\right)=0$ for all $u \in H^{n-p}(\mathrm{BO})$ and for all $p \geq 0, v_{p} \in H^{p}(\mathrm{BO})$ being the $\mathrm{Wu}$ class.

Here we shall extend this result to the singular case as follows:

THEOREM 3.2. For each $n \geq 0$, if $h: H^{n}(\mathrm{BO} \times X) \rightarrow \mathbb{Z}_{2}$ is a homomorphism then there is an $n$-dimensional singular manifold $\left(M^{n}, f\right)$ with $h(w \otimes x)=\left\langle\tau^{*}(w) f^{*}(x),\left[M^{n}\right]\right\rangle$ for all $w \otimes x \in H^{n}(\mathrm{BO} \times X)$ if and only if $h\left(\mathrm{Sq}^{p}(u \otimes y)+\left(v_{p} \cdot u\right) \otimes y\right)=0$ for all $u \otimes y \in H^{n-p}(\mathrm{BO} \times X)$ and for all $p \geq 0, v_{p} \in H^{p}(\mathrm{BO})$ being the Wu class.

Proof. It is easy to see that the condition is necessary. We prove that the condition is sufficient also. Let $\left\{c_{m, i}\right\}_{i \in I_{m}}$ denote a basis for the vector space $H_{m}(X)$ over $\mathbb{Z}_{2}, m \geq 0$. Let $c^{m, i} \in H^{m}(X)$ be the cohomology class dual to $c_{m, i}$ i.e. $\left\langle c^{m, i}, c_{m, j}\right\rangle=\delta_{i j}$. Note that $\left\{c^{m, i}\right\}$ forms a basis for $H^{m}(X)$. Now, for each $c_{m, j}$ we can choose a singular manifold $\left(M_{j}^{m}, f_{j}^{m}\right)$ with $\left(f_{j}^{m}\right)_{*}\left(\left[M_{j}^{m}\right]\right)=c_{m, j},[2]$. Thus, we have

$$
\left\langle\left(f_{j}^{m}\right)^{*} c^{m, i},\left[M_{j}^{m}\right]\right\rangle=\delta_{i j} .
$$

Now,

$$
H^{n}(\mathrm{BO} \times X)=\bigoplus_{l=0}^{n} H^{l}(\mathrm{BO}) \otimes H^{n-l}(X)
$$

Define,

$$
h_{i}^{0}: H^{0}(\mathrm{BO}) \rightarrow \mathbb{Z}_{2}
$$

by

$$
h_{i}^{0}(1)=h\left(1 \otimes c^{n, i}\right) .
$$

Clearly, $h_{i}^{0}$ satisfies the condition given in Result (3.1) and so there exists a manifold $V_{i}^{0}$ such that

$$
h_{i}^{0}(1)=\left\langle\tau^{*}(1),\left[V_{i}^{0}\right]\right\rangle=\left\langle 1,\left[V_{i}^{0}\right]\right\rangle,
$$

for each $i \in I_{n}$. 
Define $h_{i}^{1}: H^{1}(\mathrm{BO}) \rightarrow \mathbb{Z}_{2}$ by

$$
\begin{aligned}
h_{i}^{1}(w)= & h\left(w \otimes c^{n-1, i}\right) \\
& +\sum_{j \in I_{n}}\left\langle\tau^{*}(w)\left(f_{j}^{n} \pi\right)^{*}\left(c^{n-1, i}\right),\left[M_{j}^{n} \times V_{j}^{0}\right]\right\rangle \\
= & h\left(w \otimes c^{n-1, i}\right) \\
& +\sum_{j}\left\langle\tau^{*} w \cdot\left(\left(f_{j}^{n}\right)^{*} c^{n-1, i} \otimes 1\right),\left[M_{j}^{n} \times V_{j}^{0}\right]\right\rangle .
\end{aligned}
$$

Now,

$$
\begin{aligned}
h_{i}^{1}\left(\mathbf{S q}^{1}(1)+v_{1} \cdot 1\right) & \\
\quad= & h\left(v_{1} \otimes c^{n-1, i}\right)+\sum_{j}\left\langle\tau^{*} v_{1} \cdot\left(\left(f_{j}^{n}\right)^{*} c^{n-1, i} \otimes 1\right),\left[M_{j}^{n} \times V_{j}^{0}\right]\right\rangle \\
& =h\left(\mathbf{S q}^{1}\left(1 \otimes c^{n-1, i}\right)\right)+\sum_{j}\left\langle\mathrm{Sq}^{1}\left(\left(f_{j}^{n}\right)^{*} c^{n-1, i} \otimes 1\right),\left[M_{j}^{n} \times V_{j}^{0}\right]\right\rangle \\
& =h\left(1 \otimes \mathrm{Sq}^{1} c^{n-1, i}\right)+\sum_{j}\left\langle\left(f_{j}^{n}\right)^{*} \mathrm{Sq}^{1} c^{n-1, i},\left[M_{j}^{n}\right]\right\rangle\left\langle 1,\left[V_{j}^{0}\right]\right\rangle .
\end{aligned}
$$

Since, $\mathrm{Sq}^{1} c^{n-1, i} \in H^{n}(X)$, there is a subset $K_{n} \subset I_{n}$ such that

$$
\mathrm{Sq}^{1} c^{n-1, i}=\sum_{k \in K_{n}} c^{n, k}
$$

Therefore,

$$
\begin{aligned}
h_{i}^{1}\left(\mathbf{S q}^{1}(1)+v_{1} \cdot 1\right) & \\
& =\sum_{k \in K_{n}} h\left(1 \otimes c^{n, k}\right)+\sum_{j} \sum_{k \in K_{n}}\left\langle\left(f_{j}^{n}\right)^{*} c^{n, k},\left[M_{j}^{n}\right]\right\rangle h_{j}^{0}(1) \\
& =\sum_{k} h_{k}^{0}(1)+\sum_{k} h_{k}^{0}(1), \quad \text { since }\left\langle\left(f_{j}^{n}\right)^{*} c^{n, k},\left[M_{j}^{n}\right]\right\rangle=\delta_{k j} \\
& =0 .
\end{aligned}
$$

So, by Result (3.1), there exists a manifold $V_{i}^{1}$ such that

$$
h_{i}^{1}(w)=\left\langle\tau^{*} w,\left[V_{i}^{1}\right]\right\rangle,
$$

for each $i \in I_{n-1}$.

Now, using induction, we define $h_{i}^{l}: H^{l}(\mathrm{BO}) \rightarrow \mathbb{Z}_{2}$ by

$$
\begin{aligned}
h_{i}^{l}(w)= & h\left(w \otimes c^{n-l, i}\right) \\
& +\sum_{\substack{j \in I_{n-m} \\
0 \leq m<1}}\left\langle\tau^{*} w \cdot\left(\left(f_{j}^{n-m}\right)^{*} c^{n-l, i} \otimes 1\right),\left[M_{j}^{n-m} \times V_{j}^{m}\right]\right\rangle
\end{aligned}
$$

where $1 \leq l \leq n$, and each $V_{j}^{m}$ is given by $h_{j}^{m}(m<l)$. 
Now, it is enough to show that $h_{i}^{l}$ satisfies the condition given in (3.1). For if it is so, then there exists a family $\left\{V_{i}^{l}\right\}_{i \in I_{n-l}}$ of manifolds such that for each $i \in I_{n-l}$,

$$
h_{i}^{l}(w)=\left\langle\tau^{*} w,\left[V_{i}^{l}\right]\right\rangle \quad(1 \leq l \leq n) .
$$

Also, we already have a family $\left\{V_{i}^{0}\right\}_{i \in I_{n}}$ of manifolds such that

$$
h_{i}^{0}(1)=\left\langle 1,\left[V_{i}^{0}\right]\right\rangle,
$$

for each $i \in I_{n}$. It is then easy to see that the given homomorphism $h: H^{n}(\mathrm{BO} \times X) \rightarrow \mathbb{Z}_{2}$ corresponds to the singular manifold $\left(M^{n}, f\right)$ given by

$$
M^{n}=\bigsqcup M_{i}^{n-l} \times V_{i}^{l} \text { and } f=\bigsqcup\left(f_{i}^{n-l} \pi\right),
$$

where the disjoint union $\sqcup$ is taken over all $i \in I_{n-l}$ and all $0 \leq l \leq$ $n$, and $\pi: M_{i}^{n-l} \times V_{i}^{l} \rightarrow M_{i}^{n-l}$ denotes the projection map.

Note that, for each $p \geq 0$ and for each $u \in H^{l-p}(\mathrm{BO})$,

$$
h_{i}^{l}\left(\mathrm{Sq}^{p} u+v_{p} \cdot u\right)=\mathrm{I}+\mathrm{II}+\mathrm{III},
$$

where

$$
\begin{aligned}
& \mathbf{I}=h\left(\left(\mathbf{S q}^{p} u+v_{p} \cdot u\right) \otimes c^{n-l, i}\right) \\
& =h\left(\mathbf{S q}^{p} u \otimes c^{n-l, i}+\left(v_{p} \cdot u\right) \otimes c^{n-l, i}\right) \\
& =h\left(\sum_{\substack{r+s=p \\
r \neq p}} \mathrm{Sq}^{r} u \otimes \mathrm{Sq}^{s} c^{n-l, i}\right), \quad \text { by hypothesis on } h \text {, } \\
& =\sum_{\substack{r+s=p \\
r \neq p}} h\left(\mathrm{Sq}^{r} u \otimes \mathrm{Sq}^{s} c^{n-l, i}\right), \\
& \mathrm{II}=\sum_{\substack{j \in I_{n-m} \\
0 \leq m<l}}\left\langle\tau^{*}\left(\mathbf{S q}^{p} u\right)\left(\left(f_{j}^{n-m}\right)^{*} c^{n-l, i} \otimes 1\right),\left[M_{j}^{n-m} \times V_{j}^{m}\right]\right\rangle \\
& =\sum_{j, m}\left\langle\mathrm{Sq}^{p}\left(\tau^{*} u\right)\left(\left(f_{j}^{n-m}\right)^{*} c^{n-l, i} \otimes 1\right),\left[M_{j}^{n-m} \times V_{j}^{m}\right]\right\rangle, \quad \text { and } \\
& \mathrm{III}=\sum_{j, m}\left\langle\tau^{*}\left(v_{p} \cdot u\right)\left(\left(f_{j}^{n-m}\right)^{*} c^{n-l, i} \otimes 1\right),\left[M_{j}^{n-m} \times V_{j}^{m}\right]\right\rangle \\
& =\sum_{j, m}\left\langle\mathrm{Sq}^{p}\left(\tau^{*} u\left(\left(f_{j}^{n-m}\right)^{*} c^{n-l, i} \otimes 1\right)\right),\left[M_{j}^{n-m} \times V_{j}^{m}\right]\right\rangle .
\end{aligned}
$$


So,

$$
\begin{aligned}
\mathrm{II}+\mathrm{III} & =\sum_{j, m} \sum_{\substack{r+s=p \\
r \neq p}}\left\langle\mathrm{Sq}^{r}\left(\tau^{*} u\right)\left(\mathrm{Sq}^{s}\left(f_{j}^{n-m}\right)^{*} c^{n-l, i} \otimes 1\right),\left[M_{j}^{n-m} \times V_{j}^{m}\right]\right\rangle \\
& =\sum_{j, m} \sum_{\substack{r+s=p \\
r \neq p}}\left\langle\mathrm{Sq}^{r}\left(\tau^{*} u\right)\left(\left(f_{j}^{n-m}\right)^{*} \operatorname{Sq}^{s} c^{n-l, i} \otimes 1\right),\left[M_{j}^{n-m} \times V_{j}^{m}\right]\right\rangle .
\end{aligned}
$$

Now, since $\mathrm{Sq}^{s} c^{n-l, i} \in H^{n-l+s}(X)$, there is a subset $K_{n-l+s}$ of $I_{n-l+s}$ such that

$$
\mathrm{Sq}^{s} c^{n-l, i}=\sum_{k \in K_{n-l+s}} c^{n-l+s, k}, \quad(1 \leq s \leq p) .
$$

So,

(1) $h\left(\mathrm{Sq}^{r} u \otimes \mathrm{Sq}^{s} c^{n-l, i}\right)$

$$
\begin{aligned}
& =\sum_{k \in K_{n-l+s}} h\left(\mathrm{Sq}^{r} u \otimes c^{n-l+s, k}\right) \\
& =\sum_{k}\left\{\sum_{\substack{j, m \\
(m<l-s)}}\left\langle\tau^{*}\left(\mathrm{Sq}^{r} u\right)\left(\left(f_{j}^{n-m}\right)^{*} c^{n-l+s, k} \otimes 1\right),\left[M_{j}^{n-m} \times V_{j}^{m}\right]\right\rangle\right. \\
& \left.+\left\langle\tau^{*}\left(\mathrm{Sq}^{r} u\right),\left[V_{k}^{l-s}\right]\right\rangle\right\}, \\
& =\sum_{\substack{j, m \\
(m<l-s)}} \operatorname{noting}^{n-m a t} l-s<l \\
& \left.+\sum_{k}\left\langle\operatorname{Sq}^{r}\left(\tau^{*} u\right),\left[V_{k}^{l-s}\right]\right\rangle .\left(\left(f_{j}^{n-m}\right)^{*} \operatorname{Sq}^{s} c^{n-l, i} \otimes 1\right),\left[M_{j}^{n-m} \times V_{j}^{m}\right]\right\rangle
\end{aligned}
$$

Also,

(*) $\sum_{\substack{j, m \\(l-s \leq m<l)}}\left\langle\mathrm{Sq}^{r}\left(\tau^{*} u\right)\left(\left(f_{j}^{n-m}\right)^{*} \mathrm{Sq}^{s} c^{n-l, i} \otimes 1\right),\left[M_{j}^{n-m} \times V_{j}^{m}\right]\right\rangle$
$\quad=\sum_{j}\left\langle\mathrm{Sq}^{r}\left(\tau^{*} u\right)\left(\left(f_{j}^{n-l+s}\right)^{*} \mathrm{Sq}^{s} c^{n-l, i} \otimes 1\right),\left[M_{j}^{n-l+s} \times V_{j}^{l-s}\right]\right\rangle$,

by dimensional consideration, since $m \geq l-s$. Further, we note that $u$ is a polynomial in Stiefel-Whitney classes of $\mathrm{BO}$, so that $\mathrm{Sq}^{r}\left(\tau^{*} u\right)$ is 
a polynomial in Stiefel-Whitney classes of $M_{j}^{n-l+s} \times V_{j}^{l-s}$. Therefore the above expression $(*)$ becomes equal to

$$
\begin{aligned}
& \sum_{j}\left\langle\left(f_{j}^{n-l+s}\right)^{*} \mathrm{Sq}^{s} c^{n-l, i},\left[M_{j}^{n-l+s}\right]\right\rangle\left\langle\mathrm{Sq}^{r}\left(\tau^{*} u\right),\left[V_{j}^{l-s}\right]\right\rangle \\
& \quad=\sum_{j} \sum_{k \in K_{n-l+s}}\left\langle\left(f_{j}^{n-l+s}\right)^{*} c^{n-l+s, k},\left[M_{j}^{n-l+s}\right]\right\rangle\left\langle\mathrm{Sq}^{r}\left(\tau^{*} u\right),\left[V_{j}^{l-s}\right]\right\rangle \\
& \quad=\sum_{k}\left\langle\mathrm{Sq}^{r}\left(\tau^{*} u\right),\left[V_{k}^{l-s}\right]\right\rangle .
\end{aligned}
$$

Hence, combining I with (1) and II + III with (2), it follows that

$$
h_{i}^{l}\left(\mathrm{Sq}^{p} u+v_{p} \cdot u\right)=\mathrm{I}+\mathrm{II}+\mathrm{III}=0 .
$$

That is, $h_{i}^{l}$ satisfies the condition given in (3.1).

Now, consider the universal bundle $\gamma: \mathrm{EO} \rightarrow \mathrm{BO}$ and the cartesian product $\gamma \times \gamma$ over $\mathrm{BO} \times \mathrm{BO}$. Let $\mu: \mathrm{BO} \times \mathrm{BO} \rightarrow \mathrm{BO}$ be the classifying map of $\gamma \times \gamma . \mu$ has the property that

$$
\mu^{*}\left(W_{i}\right)=\sum_{k=0}^{i} W_{k} \otimes W_{i-k} .
$$

The product of two singular manifolds $\left(M^{m}, f\right)$ and $\left(M^{n}, g\right)$ in BO is given by $\left(M^{m} \times M^{n}, \mu \circ(f \times g)\right)$, and this product induces a multiplication in $N_{*}(\mathrm{BO})$ given by

$$
\left[M^{m}, f\right] \times\left[M^{n}, g\right]=\left[M^{m} \times M^{n}, \mu \circ(f \times g)\right],
$$

which makes $N_{*}(\mathrm{BO})$ an algebra over $\mathbb{Z}_{2}$.

Analogous to [4], we have

LeMma 3.3. The Stiefel-Whitney numbers

$$
\left\langle W_{2 i_{1}} \cdots W_{2 i_{r}}(\mu \circ(g \times g))^{*}\left(W_{2 i_{r+1}} \cdots W_{2 i_{r+s}}\right),[N \times N]\right\rangle
$$

of the product $(N, g) \times(N, g)$ in $\mathrm{BO}$ are equal to

$$
\left\langle W_{i_{1}} \cdots W_{i_{r}} g^{*}\left(W_{i_{r+1}} \cdots W_{i_{r+s}}\right),[N]\right\rangle,
$$

while the numbers

$$
\left\langle W_{j_{1}} \cdots W_{j_{p}}(\mu \circ(g \times g))^{*}\left(W_{j_{p+1}} \cdots W_{j_{p+q}}\right),[N \times N]\right\rangle
$$

are zero if some $j_{h}$ is odd.

Proof. Routine verification. 
TheOREM 3.4. Let $\left(M^{2 n}, f\right)$ be a singular manifold in $\mathrm{BO}$, such that

$$
\left\langle W_{j_{1}} \cdots W_{j_{p}} f^{*}\left(W_{j_{p+1}} \cdots W_{j_{p+q}}\right),\left[M^{2 n}\right]\right\rangle=0,
$$

whenever some $j_{h}$ is odd. Then

$$
\left[M^{2 n}, f\right]=\left[\left(N^{n}, g\right) \times\left(N^{n}, g\right)\right] \text { in } N_{2 n}(\mathrm{BO}) \text {. }
$$

Proof. We shall construct a singular manifold $\left(N^{n}, g\right)$ in BO whose Stiefel-Whitney numbers

$$
\left\langle W_{i_{1}} \cdots W_{i_{r}} g^{*}\left(W_{i_{r+1}} \cdots W_{i_{r+s}}\right),\left[N^{n}\right]\right\rangle
$$

are equal to

$$
\left\langle W_{2 i_{1}} \cdots W_{2 i_{r}} f^{*}\left(W_{2 i_{r+1}} \cdots W_{2 i_{r+s}}\right),\left[M^{2 n}\right]\right\rangle .
$$

This will imply that $\left(M^{2 n}, f\right)$ is cobordant to $\left(N^{n}, g\right) \times\left(N^{n}, g\right)$, by (3.3).

Let $R^{n} \subset H^{n}(\mathrm{BO} \times \mathrm{BO})$ be the vector space generated by all elements of the form $\operatorname{Sq}^{p}(x \otimes y)+\left(v_{p} \cdot x\right) \otimes y$. The Stiefel-Whitney numbers of each manifold $\left(N^{n}, g\right)$ determine a homomorphism

$$
h_{N}: H^{n}(\mathrm{BO} \times \mathrm{BO}) \rightarrow \mathbb{Z}_{2}
$$

given by $h_{N}(x \otimes y)=\left\langle(\tau, g)^{*}(x \otimes y),[N]\right\rangle$, and by Theorem (3.2) we know that a given homomorphism $H^{n}(\mathrm{BO} \times \mathrm{BO}) \rightarrow \mathbb{Z}_{2}$ corresponds to a singular manifold in $\mathrm{BO}$ if and only if it annihilates $R^{n}$.

Define the "doubling homomorphism"

$$
d: H^{*}(\mathrm{BO} \times \mathrm{BO}) \rightarrow H^{*}(\mathrm{BO} \times \mathrm{BO})
$$

by

$$
d\left(W_{i} \otimes W_{j}\right)=W_{2 i} \otimes W_{2 j} .
$$

Let $\left(M^{2 n}, f\right)$ satisfy the hypothesis of Theorem (3.4). Then we shall show that $h_{M} \circ d: H^{n}(\mathrm{BO} \times \mathrm{BO}) \rightarrow \mathbb{Z}_{2}$ annihilates $R^{n}$. This will prove the existence of the required manifold $\left(N^{n}, g\right)$.

Let $I \subset H^{*}(\mathrm{BO} \times \mathrm{BO})$ denote the ideal generated by the family $\left\{W_{i} \otimes 1,1 \otimes W_{i}\right\}_{i \text { odd }}$. Note that

$$
\begin{aligned}
& \mathrm{Sq}^{2 i} d\left(W_{j} \otimes 1\right)=\left(\mathrm{Sq}^{2 i} W_{2 j}\right) \otimes 1 \\
& =\left(\sum_{k=0}^{2 i}\left(\begin{array}{c}
2 j-2 i+k-1 \\
k
\end{array}\right) W_{2 i-k} W_{2 j+k}\right) \otimes 1,
\end{aligned}
$$


where $\left(\begin{array}{l}p \\ q\end{array}\right)$ denotes the binomial coefficients reduced modulo 2 . Therefore using the fact that

$$
\left(\begin{array}{c}
2 j-2 i+2 l-1 \\
2 l
\end{array}\right)=\left(\begin{array}{c}
j-i+l-1 \\
l
\end{array}\right)
$$

we get

$$
\begin{aligned}
\mathrm{Sq}^{2 i} d\left(W_{j} \otimes 1\right) & \equiv\left(\sum_{l=0}^{i}\left(\begin{array}{c}
j-i+l-1 \\
l
\end{array}\right) W_{2 i-2 l} W_{2 j+2 l}\right) \otimes 1 \bmod I \\
& \equiv d\left(\mathrm{Sq}^{i}\left(W_{j} \otimes 1\right)\right) \bmod I .
\end{aligned}
$$

Similarly, $\mathrm{Sq}^{2 i} d\left(1 \otimes W_{j}\right) \equiv d\left(\mathrm{Sq}^{i}\left(1 \otimes W_{j}\right)\right) \bmod I$. Further, if

$$
\begin{aligned}
& \mathrm{Sq}^{2 i} d(x \otimes y) \equiv d\left(\mathrm{Sq}^{i}(x \otimes y)\right) \bmod I \text { and } \\
& \mathrm{Sq}^{2 i} d(x \otimes y) \equiv d\left(\mathrm{Sq}^{i}\left(x^{\prime} \otimes y^{\prime}\right)\right) \bmod I,
\end{aligned}
$$

then

$$
\begin{array}{rl}
\mathrm{Sq}^{2 i} & d\left((x \otimes y)\left(x^{\prime} \otimes y^{\prime}\right)\right) \\
& \equiv \sum_{p+q=i}\left(\mathrm{Sq}^{2 p} d(x \otimes y)\right)\left(\mathrm{Sq}^{2 q} d\left(x^{\prime} \otimes y^{\prime}\right)\right) \bmod I \\
& \equiv \sum_{p+q=i}\left(d\left(\mathrm{Sq}^{p}(x \otimes y)\right)\right)\left(d\left(\mathrm{Sq}^{q}\left(x^{\prime} \otimes y^{\prime}\right)\right)\right) \bmod I \\
& \equiv d\left(\mathrm{Sq}^{i}\left((x \otimes y)\left(x^{\prime} \otimes y^{\prime}\right)\right)\right) \quad \bmod I .
\end{array}
$$

Hence, by induction, it follows that

$$
\mathrm{Sq}^{2 i} d(x \otimes y) \equiv d\left(\mathrm{Sq}^{i}(x \otimes y)\right) \quad \bmod I,
$$

for each $x \otimes y \in H^{*}(\mathrm{BO} \times \mathrm{BO})$.

It is simple to verify that $I$ is closed under Steenrod squaring operation. Applying induction on $p$, one gets

$$
d\left(v_{p} \otimes 1\right) \equiv\left(v_{2 p} \otimes 1\right) \quad \bmod I .
$$

Now, consider the manifold $\left(M^{2 n}, f\right)$. By the hypothesis on $\left(M^{2 n}, f\right)$ we have

$$
h_{M}\left(I^{2 n}\right)=0, \quad \text { where } I^{2 n}=I \cap H^{2 n}(\mathrm{BO} \times \mathrm{BO}) .
$$

Therefore, for any generator $\operatorname{Sq}^{p}(x \otimes y)+\left(v_{p} \otimes 1\right)(x \otimes y)$ of $R^{n}$ we have, using the congruences established above,

$$
\begin{aligned}
& \left(h_{M} \circ d\right)\left(\mathrm{Sq}^{p}(x \otimes y)+\left(v_{p} \otimes 1\right)(x \otimes y)\right) \\
& \quad=h_{M}\left(\operatorname{Sq}^{2 p}(d(x \otimes y))+\left(v_{2 p} \otimes 1\right) d(x \otimes y)+\left(\text { terms in } I^{2 n}\right)\right) \\
& \quad=0 .
\end{aligned}
$$


That is, $h_{M} \circ d$ annihilates $R^{n}$ and so by Theorem (3.2) there exists a singular manifold $\left(N^{n}, g\right)$ in BO such that $h_{M} \circ d=h_{N}$. Hence, the theorem follows.

4. Cobcat and singular bordism in $\mathrm{BO}$. Analogous to [1], we define the cobcat for a singular manifold $\left(M^{n}, f\right)$ in $X$ as follows

Definition. Cobcat $\left(M^{n}, f\right)$ is the smallest positive integer $k$ such that for each $m, 0 \leq m \leq n$, the number

$$
\left\langle W_{i_{1}} \cdots W_{i_{p}} f^{*}\left(x_{j_{1}} \cdots x_{j_{q}}\right),\left[M^{n}\right]\right\rangle=0
$$

for all partitions $i_{1}+\cdots+i_{p}$ of $m$ and for all partitions $j_{1}+\cdots+j_{q}$ of $n-m$, with $k \leq p+q \leq n \quad\left(x_{j_{h}} \in H^{j_{h}}(X)\right.$ for all $\left.j_{h}\right)$. If no such $k$ exists define $\operatorname{cobcat}\left(M^{n}, f\right)=n+1$.

REMARK 4.1. (a) $\operatorname{Cobcat}\left(M^{n}\right) \leq \operatorname{cobcat}\left(M^{n}, f\right)$,

(b) $\operatorname{cobcat}\left(M^{n}, f\right)=1$ if and only if $\left(M^{n}, f\right)$ bounds,

(c) $\operatorname{cobcat}\left(M^{n}, f\right) \leq \operatorname{nil}\left(\operatorname{Im}(\tau, f)^{*}\right) \leq \operatorname{cat}(\tau, f) \leq \operatorname{cat}\left(M^{n}\right)$,

(d)

$\operatorname{cobcat}\left(M_{1}^{n} \sqcup M_{2}^{n}, f_{1} \sqcup f_{2}\right) \leq \max \left\{\operatorname{cobcat}\left(M_{1}^{n}, f_{1}\right), \operatorname{cobcat}\left(M_{2}^{n}, f_{2}\right)\right\}$.

Now we shall discuss the singular version of some results proved in [1]. Let $P^{*}$ be the Poincare algebra associated to the singular manifold $\left(M^{n}, f\right)$ in $X$. As in [1], an element $z$ of any graded algebra $A^{*}$ will be called $k$-decomposable if it is zero or is the sum of the products $z_{1} \cdot z_{2} \cdot \cdots \cdot z_{p}$ where $z_{i} \in A^{*}$ with $\operatorname{dim} z_{i}>0$ for each $i$, and $p \geq k$.

Proposition 4.2. Let $\operatorname{cobcat}\left(M^{n}, f\right) \leq k$.

(a) If $z \in P^{*}$ is $k$-decomposable, then $z$ is zero.

(b) If $z \in P^{*}$ is $(k-1)$-decomposable and $\operatorname{dim} z<n$ then $z$ is zero.

Proof. Note that any $k$-decomposable element $z$ of $H^{*}(\mathrm{BO} \times X) \cong$ $H^{*}(\mathrm{BO}) \otimes H^{*}(X)$ can be written as a sum of the products $z_{1} \cdot z_{2} \ldots \ldots$ $z_{p}$, where each $z_{i}$ is of the type $W_{j} \otimes 1$ or $1 \otimes x_{j}$, and $p \geq k$. Also for any $z^{\prime} \in H^{n-\operatorname{dim} z}(\mathrm{BO} \times X)$ we have

$$
\left\langle(\tau, f)^{*} z_{1}(\tau, f)^{*} z_{2} \cdots(\tau, f)^{*} z_{p}(\tau, f)^{*} z^{\prime},\left[M^{n}\right]\right\rangle=0,
$$

since $\operatorname{cobcat}\left(M^{n}, f\right) \leq k$ and $p \geq k$. Hence (a) follows, using the fact that any $k$-decomposable element of $P^{*}$ can be obtained from a $k$-decomposable element of $H^{*}(\mathrm{BO} \times X)$.

As in ([1], 1.2), (b) follows from (a). 
From now on, the ambient space $X$ will be taken to be the universal base space $\mathrm{BO}$ and $\left(M^{n}, f\right)$ will denote a singular manifold in $\mathrm{BO}$ with $\operatorname{cobcat}\left(M^{n}, f\right) \leq 3$.

LEMMA 4.3. (a) If $z\left(W_{i} \otimes 1\right)=0$ and $z\left(1 \otimes W_{i}\right)=0$ in $P^{*}$, where $z \in H^{n-i}(\mathrm{BO} \times \mathrm{BO})$ and $0<i<n$, then $z=0$ in $P^{*}$.

(b) For $j>0$,

$$
W_{2 j+1} \otimes 1= \begin{cases}\mathrm{Sq}^{1}\left(W_{2 j} \otimes 1\right) & \text { if } 2 j+1<n, \\ 0 & \text { if } 2 j+1=n,\end{cases}
$$

and

$$
1 \otimes W_{2 j+1}=\mathrm{Sq}^{1}\left(1 \otimes W_{2 j}\right) \quad \text { if } 2 j+1<n
$$

in $P^{*}$.

Proof. (a) By the hypothesis, the last proposition and the fact that $\operatorname{cobcat}\left(M^{n}, f\right) \leq 3$, we have

$$
\left\langle(\tau, f)^{*} z(\tau, f)^{*} z^{\prime},\left[M^{n}\right]\right\rangle=\left\langle(\tau, f)^{*}\left(z \cdot z^{\prime}\right),\left[M^{n}\right]\right\rangle=0
$$

for all $z^{\prime} \in H^{i}(\mathrm{BO} \times \mathrm{BO})$. So $z=0$ in $P^{*}$.

(b) Note that

$$
\mathrm{Sq}^{1}\left(W_{2 j} \otimes 1\right)=\left(W_{1} \otimes 1\right)\left(W_{2 j} \otimes 1\right)+W_{2 j+1} \otimes 1 .
$$

If $2 j+1<n$ then $\left(W_{1} \otimes 1\right)\left(W_{2 j} \otimes 1\right)$, being decomposable, is zero in $P^{*}$. If $2 j+1=n$, then $\left(W_{1} \otimes 1\right)\left(W_{2 j} \otimes 1\right)=\mathrm{Sq}^{1}\left(W_{2 j} \otimes 1\right)$ in $P^{*}$. For the last part of (b) one has

$$
\mathrm{Sq}^{1}\left(1 \otimes W_{2 j}\right)=\left(1 \otimes W_{1}\right)\left(1 \otimes W_{2 j}\right)+1 \otimes W_{2 j+1} \text {. }
$$

LEMMA 4.4. If $n$ is even and $n>2$, then $W_{i} \otimes 1=0$ and $1 \otimes W_{i}=0$ in $P^{*}$ for all odd $i$.

Proof. By Lemma (4.3), it is enough to show that

(a) $\left(W_{i} \otimes 1\right)\left(W_{n-i} \otimes 1\right)=0$,

(b) $\left(W_{i} \otimes 1\right)\left(1 \otimes W_{n-i}\right)=0$,

(c) $\left(1 \otimes W_{i}\right)\left(1 \otimes W_{n-i}\right)=0$ in $P^{*}$ for all odd $i$.

For (a), let $i=1$; then

$$
\left(W_{1} \otimes 1\right)\left(W_{n-1} \otimes 1\right)=\operatorname{Sq}^{1}\left(W_{n-1} \otimes 1\right)=\operatorname{Sq}^{1} \operatorname{Sq}^{1}\left(W_{n-2} \otimes 1\right)=0
$$

in $P^{*}$, using (4.3) and the fact that $\mathrm{Sq}^{1} \mathrm{Sq}^{1}=0$. Now let $i=2 j+1$, 
$j>0$ and $n-i=2 k+1, k>0$; then by (4.3)

$$
\begin{aligned}
&\left(W_{i} \otimes 1\right)\left(W_{n-i} \otimes 1\right)=\mathrm{Sq}^{1}\left(W_{2 j} \otimes 1\right) \mathrm{Sq}^{1}\left(W_{2 k} \otimes 1\right) \\
&=\mathrm{Sq}^{1}\left(\left(W_{2 j} \otimes 1\right) \mathrm{Sq}^{1}\left(W_{2 k} \otimes 1\right)\right) \\
&=\left(W_{1} \otimes 1\right)\left(W_{2 j} \otimes 1\right) \mathrm{Sq}^{1}\left(W_{2 k} \otimes 1\right)=0
\end{aligned}
$$

in $P^{*}$, as it is 3-decomposable. Hence (a) follows. For (b), using the same technique as in $(\mathrm{a})$, we have $\left(W_{i} \otimes 1\right)\left(1 \otimes W_{n-i}\right)=0$ in $P^{*}$ for all odd $i<n-1$. However, for $i=n-1$, we have by (4.3)

$$
\begin{aligned}
\left(W_{n-1} \otimes 1\right)\left(1 \otimes W_{1}\right)=\mathrm{Sq}^{1}\left(W_{n-2} \otimes 1\right)\left(1 \otimes W_{1}\right) \\
=\mathrm{Sq}^{1}\left(\left(W_{n-2} \otimes 1\right)\left(1 \otimes W_{1}\right)\right)+\left(W_{n-2} \otimes 1\right) \mathrm{Sq}^{1}\left(1 \otimes W_{1}\right) \\
=\left(W_{1} \otimes 1\right)\left(W_{n-2} \otimes 1\right)\left(1 \otimes W_{1}\right) \\
\quad+\left(W_{n-2} \otimes 1\right)\left(1 \otimes W_{1}\right)\left(1 \otimes W_{1}\right)=0
\end{aligned}
$$

in $P^{*}$, as it is 3-decomposable. Thus (b) follows. Now, (c) can be proved by the same technique used in (a) and (b) above.

Proposition 4.5. If $\left(M^{n}, f\right)$ is a non-bounding n-dimensional singular manifold in $\mathrm{BO}$ with $\operatorname{cobcat}\left(M^{n}, f\right) \leq 3$, where $n$ is even and $n>2$, then $\left(M^{n}, f\right)$ is cobordant to a product $(N, g) \times(N, g)$ in $\mathrm{BO}$, where $(N, g)$ is also non-bounding and $\operatorname{cobcat}(N, g) \leq 3$.

Proof. By Theorem (3.4) and Lemma (4.4), there exists a singular manifold $(N, g)$ is $\mathrm{BO}$ of dimension $n / 2$ such that $\left(M^{n}, f\right)$ is cobordant to the product $(N, g) \times(N, g)$. Also,

$$
\begin{aligned}
\left\langle W_{i_{1}} \cdots W_{i_{p}} g^{*}\left(W_{i_{p+1}} \cdots W_{i_{p+q}}\right),[N]\right\rangle \\
\quad=\left\langle W_{2 i_{1}} \cdots W_{2 i_{p}} f^{*}\left(W_{2 i_{p+1}} \cdots W_{2 i_{p+q}}\right),[M]\right\rangle,
\end{aligned}
$$

where $i_{1}+\cdots+i_{p+q}=n / 2$ is a partition of $n / 2$. Hence the proposition follows.

In the above proposition one can observe that if the underlying manifold $M^{n}$ in $\left(M^{n}, f\right)$ were a boundary then $N$ in $(N, g)$ would also be a boundary. Further, using induction, one can easily get the following

Corollary 4.6. Let $\left(M^{n}, f\right)$ be an n-dimensional singular manifold in $\mathrm{BO}$ with $\operatorname{cobcat}\left(M^{n}, f\right) \leq 3$. Let $n=2^{r} \cdot m$ where either $m$ is odd and $m \geq 3$, or $m=2$. Then either $\left(M^{n}, f\right)$ is a boundary or else $\left(M^{n}, f\right)$ is cobordant to $(N, g)^{2^{r}}$, where $(N, g)$ is a non-bounding $m$-dimensional singular manifold in $\mathrm{BO}$ with $\operatorname{cobcat}(N, g) \leq 3$. 
Finally, in view of the above results and the fact that $N_{2}(\mathrm{BO})$ is generated by the bordism classes $\left[\left(R P^{1}, \tau_{1}\right)^{2}\right],\left[R P^{2}, \tau_{1}\right]$ and $\left[R P^{2}, c\right]$, where $\tau_{1}: R P^{i} \rightarrow \mathrm{BO}$ is the classifying map of the canonical line bundle over $R P^{i}(i=1,2)$ and $c: R P^{2} \rightarrow \mathrm{BO}$ is the constant map, we can make the following remarks.

REMARK 4.7. Let $\left(M^{n}, f\right)$ be as in (4.6) and $n=2^{r}, r \geq 1$. Then either $\left(M^{n}, f\right)$ is a boundary or else $\left(M^{n}, f\right)$ is cobordant to $(N, g)^{2^{r-1}}$, where $(N, g)$ is a 2-dimensional singular manifold generated by $\left(R P^{1}, \tau_{l}\right)^{2},\left(R P^{2}, \tau_{l}\right)$ and/or $\left(R P^{2}, c\right)$.

REMARK 4.8. In Remark (4.7) if, in addition, the underlying manifold $M^{n}$ in $\left(M^{n}, f\right)$ were a boundary then $(N, g)$ would be equal to exactly one of the following

(i) $\left(R P^{1}, \tau_{l}\right)^{2}$,

(ii) $\left(R P^{2}, c\right) \sqcup\left(R P^{2}, \tau_{l}\right)$, or

(iii) $\left(R P^{1}, \tau_{l}\right)^{2} \sqcup\left(R P^{2}, c\right) \sqcup\left(R P^{2}, \tau_{l}\right)$,

where $\left(M_{1}, f_{1}\right) \sqcup\left(M_{2}, f_{2}\right)=\left(M_{1} \sqcup M_{2}, f_{1} \sqcup f_{2}\right)$.

\section{REFERENCES}

[1] H. Singh, Lusternik-Schnirelmann category and cobordism, Proc. Amer. Math. Soc., 102 (1) (1988), 183-190.

[2] P. E. Conner, Differentiable Periodic Maps, Lecture Notes in Mathematics, vol. 738, Springer-Verlag, Berlin-Heidelberg-New York 1978.

[3] R. E. Stong, Notes on Cobordism Theory, Math. Notes, Princeton Univ. Press, Princeton, N.J., 1968.

[4] J. W. Milnor, On the Stiefel-Whitney numbers of complex manifolds and spin manifolds, Topology, 3 (1965), 223-230.

Received February 19, 1991 and in revised form July 8, 1991.

North EASTERn HiLl University

SHILlONG, 793003

MeghalAYA, INDIA 



\section{PACIFIC JOURNAL OF MATHEMATICS EDITORS}

\author{
V. S. VARADARAJAN \\ (Managing Editor) \\ University of California \\ Los Angeles, CA 90024-1555 \\ vsv@math.ucla.edu \\ Herbert Clemens \\ University of Utah \\ Salt Lake City, UT 84112 \\ clemens@math.utah.edu \\ F. Michael Christ \\ University of California \\ Los Angeles, CA 90024-1555 \\ christ@math.ucla.edu \\ THOMAs ENRIGHT \\ University of California, San Diego \\ La Jolla, CA 92093 \\ tenright@ucsd.edu
}

\author{
Nicholas ERCOLANI \\ University of Arizona \\ Tucson, AZ 85721 \\ ercolani@math.arizona.edu \\ R. FINN \\ Stanford University \\ Stanford, CA 94305 \\ finn@gauss.stanford.edu \\ VAUGHAN F. R. Jones \\ University of California \\ Berkeley, CA 94720 \\ vfr@math.berkeley.edu \\ Steven KerckhofF \\ Stanford University \\ Stanford, CA 94305 \\ spk@gauss.stanford.edu
}

\author{
C. C. MOORE \\ University of California \\ Berkeley, CA 94720
}

Martin ScharlemanN

University of California

Santa Barbara, CA 93106

mgscharl@henri.ucsb.edu

Harold Stark

University of California, San Diego La Jolla, CA 92093

\section{R. ARENS \\ ASSOCIATE EDITORS}

\begin{tabular}{lccc} 
R. ARENS & $\begin{array}{c}\text { E. F. BECKENBACH } \\
(1906-1982)\end{array}$ & B. H. NEUMANN & \multicolumn{1}{c}{ F. WOLF } \\
$(1904-1989)$ & K. YoshIDA \\
SUPPORTING & INSTITUTIONS \\
UNIVERSITY OF ARIZONA & UNIVERSITY OF OREGON \\
UNIVERSITY OF BRITISH COLUMBIA & UNIVERSITY OF SOUTHERN CALIFORNIA \\
CALIFORNIA INSTITUTE OF TECHNOLOGY & STANFORD UNIVERSITY \\
UNIVERSITY OF CALIFORNIA & UNIVERSITY OF HAWAII \\
MONTANA STATE UNIVERSITY & UNIVERSITY OF TOKYO \\
UNIVERSITY OF NEVADA, RENO & UNIVERSITY OF UTAH \\
NEW MEXICO STATE UNIVERSITY & WASHINGTON STATE UNIVERSITY \\
OREGON STATE UNIVERSITY & UNIVERSITY OF WASHINGTON \\
\hline
\end{tabular}

The Supporting Institutions listed above contribute to the cost of publication of this Journal, but they are not owners or publishers and have no responsibility for its content or policies.

Mathematical papers intended for publication in the Pacific Journal of Mathematics should be in typed form or offset-reproduced (not dittoed), double spaced with large margins. Please do not use built up fractions in the text of the manuscript. However, you may use them in the displayed equations. Underline Greek letters in red, German in green, and script in blue. The first paragraph must be capable of being used separately as a synopsis of the entire paper. In particular it should contain no bibliographic references. Please propose a heading for the odd numbered pages of less than 35 characters. Manuscripts, in triplicate, may be sent to any one of the editors. Please classify according to the 1991 Mathematics Subject Classification scheme which can be found in the December index volumes of Mathematical Reviews. Supply name and address of author to whom proofs should be sent. All other communications should be addressed to the managing editor, or Elaine Barth, University of California, Los Angeles, California 90024-1555.

There are page-charges associated with articles appearing in the Pacific Journal of Mathematics. These charges are expected to be paid by the author's University, Government Agency or Company. If the author or authors do not have access to such Institutional support these charges are waived. Single authors will receive 50 free reprints; joint authors will receive a total of 100 free reprints. Additional copies may be obtained at cost in multiples of 50 .

The Pacific Journal of Mathematics (ISSN 0030-8730) is published monthly except for July and August. Regular subscription rate: $\$ 190.00$ a year (10 issues). Special rate: $\$ 95.00$ a year to individual members of supporting institutions.

Subscriptions, orders for numbers issued in the last three calendar years, and changes of address should be sent to Pacific Journal of Mathematics, P.O. Box 969, Carmel Valley, CA 93924, U.S.A. Old back numbers obtainable from Kraus Periodicals Co., Route 100, Millwood, NY 10546.

The Pacific Journal of Mathematics at P.O. Box 969, Carmel Valley, CA 93924 (ISSN 0030-8730) is published monthly except for July and August. Second-class postage paid at Carmel Valley, California 93924, and additional mailing offices. Postmaster: send address changes to Pacific Journal of Mathematics, P.O. Box 969, Carmel Valley, CA 93924.

PUBLISHED BY PACIFIC JOURNAL OF MATHEMATICS, A NON-PROFIT CORPORATION Copyright (C) 1992 by Pacific Journal of Mathematics 


\section{PACIFIC JOURNAL OF MATHEMATICS}

Volume $155 \quad$ No. $2 \quad$ October 1992

Invariant subspaces and harmonic conjugation on compact abelian

201 groups

NAKHLE HABIB ASMAR, EARL ROBERT BERKSON and

ThOMAS Alastair GiLlESPIE

Cobcat and singular bordism

A. K. DAS and S. S. KHARE

Poles of Eisenstein series on $\mathrm{SL}_{n}$ induced from maximal parabolics

PAUL FEIT

On the postulation of 0-dimensional subschemes on a smooth quadric

251

SAlvatore GiUfFrida, Renato MagGioni and AlFio

RAGUSA

The Euler class for "piecewise" groups

Peter Abraham GREenberg

$L^{p}$-Fourier transforms on nilpotent Lie groups and solvable Lie groups 295 acting on Siegel domains

JUNKO INOUE

Fuchsian moduli on a Riemann surface-its Poisson structure and

Poincaré-Lefschetz duality

KATSUNORI IWASAKI

Interpolation between $H^{p}$ spaces and noncommutative generalizations. 341 I

\section{GILLES PISIER}

The braid index of generalized cables

ROBERT FONES WILLIAMS and ROBERT FONES WILLIAMS $B M O$ and Hankel operators on Bergman spaces 